\title{
Packed lunches for primary-school children: A qualitative study of parents' views
}

\author{
T. L. Griffin and M. E. Barker \\ University of Sheffield, Sheffield, UK
}

Primary school packed lunches have been reported to fall below recommended nutritional and food standards ${ }^{(1)}$. Recent improvements in nutritional content of school meals have paralleled reduced uptake ${ }^{(2)}$, suggesting greater attention should be placed on lunchbox food.

The aim of the present study was to explore parents' views about making children's lunch boxes, in order to identify influences on food choice and to provide an insight as to how content may be improved. Volunteers (nine fathers, twenty-two mothers) from staff at the University of Sheffield were recruited via email and interviewed to discuss their experiences of making packed lunches. Their children $(n$ 47, twenty-two girls) were aged between 4 and 11 years (7.41 (SD 1.98) years). All interviewees had regular experience of making a packed lunch, with twenty-six of the volunteers providing a lunchbox more than three times per week. The interview centred on typical lunchbox content, children's food preferences and school food policies. Parents were also asked to provide feedback on suggested Food Standards Agency (FSA) lunchbox menus ${ }^{(3)}$. Interviews, using a semi-thematic style were recorded, transcribed and analysed using crosssectional indexing to identify common themes and trends ${ }^{(4)}$.

The main reasons for taking packed lunches were parental concern over quality of school lunches, children's taste preferences and children wishing to sit with their friends at lunchtime. Making the packed lunch was generally not classed as an enjoyable activity but one that had become part of the household routine. Sandwiches were a popular choice, given by $94 \%$ of parents, of which $81 \%$ used brown or '50/50' (50\% white flour, $50 \%$ brown flour) bread. Preferred sandwich fillings were cheese, ham and tuna. Fruit was provided by $94 \%$ of parents, whilst only $26 \%$ gave crisps and $29 \%$ gave biscuits as part of their child's packed lunch. Other items commonly mentioned were yoghurts and cheese based snacks. It is important to acknowledge that the sample was selected from a relatively-high socio-economic population. Parents reported that their children's food preferences were driven by peer influence and pressure to consume lunch quickly. Lack of refrigeration facilities at schools also influenced content as parents discussed food safety concerns relating to lunchbox storage. Packed lunches were considered a cheaper option than school meals, which was important for some families. Parents reported that school food policies regarding snack items, such as confectionary, varied widely between the schools, from enforced restriction of such foods to no policy. The FSA menus were viewed as somewhat impractical and many parents were unaware of this resource.

The present study points to several areas that may improve children's lunchtime food choices. Integration of dining facilities for school dinners and packed lunches, with increased time for dining and provision of cold storage facilities for lunchboxes could improve lunchbox nutrition. Interventions may help to reduce negative peer pressure of 'healthy' food, and directly address negative stereotypes associated with school meals. Further research is needed to investigate experiences of socially-disadvantaged parents and to investigate children's views of packed lunches.

1. Jefferson A \& Cowbrough K (2004) The lunchbox survey. http://www.food.gov.uk/multimedia/pdfs/lunchbox2004report.pdf (accessed January 2008).

2. Nelson M \& Nicholas J (2006) First annual survey of take up of school meals in England. School Food Trust. http://www.schoolfoodtrust.org.uk/ UploadDocs/Library/Documents/sft_baseline_survey.pdf (accessed January 2008).

3. Food Standards Agency (2004) A month of lunchboxes, Week 3. http://www.food.gov.uk/news/newsarchive/2004/sep/lunchbox2 (accessed January 2008).

4. Mason J (2002) Qualitative Researching, 2nd ed. London: Sage. 